\title{
KLIPPEL-TRÉNAUNAY SYNDROME WITH BLEEDING PER RECTUM AS A MAJOR SURGICAL CONCERN; A CASE REPORT
}

\author{
Ziad Khan, Rooh UI Muqeem, Muhammad Zarin, Zubair Ahmed, Asad Maroof, Muslihuddin \\ Department of General Surgery Khyber Teaching Hospital, Peshawar - Pakistan
}

\begin{abstract}
Objectives: This case of Klippel-Trénaunay syndrome (KTS) is being shared as a clinical experience for future reference regarding the presentation and management of bleeding per rectum in KTS. Bleeding per rectum is a potentially lethal complication due to the colorectal hemangiomas in rare cases of KTS. Decision making regarding the choice of treatment in these patients is subject to many variables and different methods of medical and surgical treatments have been attempted and published in the literature. We are sharing our experience of surgical treatment for bleeding per rectum in KTS with satisfactory early postoperative outcome.
\end{abstract}

This article may be cited as: Khan Z, Muqeen RU, Zarin M, Ahmed Z, Maroof A, Muslihuddin. Klippel-Trénaunay syndrome with bleeding per rectum as a major surgical concern; A case report. J Med Sci 2020 October;28(4):384-386

\section{INTRODUCTION}

The name "Klippel-Trénaunay syndrome" (KTS) was first coined by Klippel and Trenaunay in the early 20th century for a triad of congenital anomalous conditions including capillary, venous, and lymphatic malformations classically presenting with limb hypertrophy. ${ }^{1} \mathrm{KTS}$ is a rare anomaly with an incidence of 1 in 10,000. There is no gender predisposition. ${ }^{2}$

The genetic basis of this condition is sporadic and there are controversies regarding the genes involved. ${ }^{3}$ The condition is compatible with life and commonly affects one of the lower limbs though the involvement of both lower limbs, trunk, and head has been reported in the literature. ${ }^{4} \mathrm{KTS}$ is sometimes confused with Parkes-Weber syndrome (PWS), which is a similar condition with the addition of arteriovenous fistulae. ${ }^{5}$ We present here a case of KTS with a unique and life-threatening presentation of severe bleeding per rectum requiring blood transfusions.

\section{CASE REPORT}

A 25 years old male reported to the surgical department of Khyber Teaching hospital Peshawar with a prominent limp complaining of bleeding per rectum more pronounced after defecation since early adolescence. The patient had been to multiple health care centers with the same complaints where he was misdiagnosed with con-

\section{Correspondence}

\section{Dr. Ziad Khan}

Department of General Surgery Khyber Teaching

Hospital, Peshawar - Pakistan.

Email: drziad.khan86.sk@gmail.com

Cell: +92-342-2555562

Date received: $20-11-2020$

Date revised: $12-12-2020$

Date accepted: $15-12-2020$ ditions like Ulcerative Colitis and hemorrhoids and was therefore mistreated. On careful inquiry of history, the patient revealed surgery for varicose veins in early childhood elsewhere. On Clinical examination, the patient was pale with otherwise normal vitals. Worth noticing was the obvious limb length discrepancy (Fig.1). The right lower limb was bulky above the knees and $3 \mathrm{~cm}$ longer than the left. On close inspection of the right lower limb, we found surgical scars consistent with the history of surgery for varicose veins in past. There were prominent veins, capillary malformations, and angiokeratomas on the limb. On perianal inspection, there were prominent warts around the anal orifice(Fig.2).

Multiple rectal hemangiomas were appreciated on Proctoscopy. Based on the above clinical findings diagnosis of KTS was made by a physician and a multidisciplinary approach was planned to address the issue of bleeding per rectum. Upper gastrointestinal (GI) endoscopy was done by a gastroenterologist which did not show any abnormality. Colonoscopy of the patient revealed anal warts and hemangiomas from the rectum up to the splenic flexure.

The rest of the colon was reported normal. Hence Colorectal Hemangiomas were declared as the cause of persistent bleeding per rectum and need of transfusions in this case. As vascular malformations, in this case, were part of KTS, therefore CT was planned to evaluate the pelvic anatomy. CT scan revealed a thick-walled rectosigmoid with tortuous structures (anomalous vessels) running along its left lateral wall and hypodense lesion in the same location abutting the left pelvic wall (possibly vascular malformation) (Fig.3). After the hemoglobin level of the patient was optimized, the departmental meeting developed a consensus to take an interventional radiol- 
ogist on board for consideration to chemo-embolize the anomalous vessels. The idea was declined by the radiology department on the ground that embolization may risk the colon as chances of ischemia were highly expected.

As all conservative measures had failed and minimal invasive radiological intervention was not possible, surgical option was discussed and planned. The patient was explored via midline laparotomy incision. Per operative, we found that the sigmoid and rectum were studded with hemangiomas (Fig.4).

Surgical interventions as per pre-op plan included ligation of inferior mesenteric and internal iliac arteries, Hartman procedure, and injection of phenol in almond oil into the rectal stump. The patient recovered uneventfully and the postoperative course was also uneventful.

The patient was mobilized and orally allowed on the first post-operative day. The catheter was removed on the third postoperative day. The only postoperative complication was surgical site infection which was managed conservatively.

The patient did not complain of any bleeding per rectum or stoma postoperatively and maintained an optimum hemoglobin level. Significant reduction in number and size of hemangiomas was noticed on examination under anesthesia after two weeks.

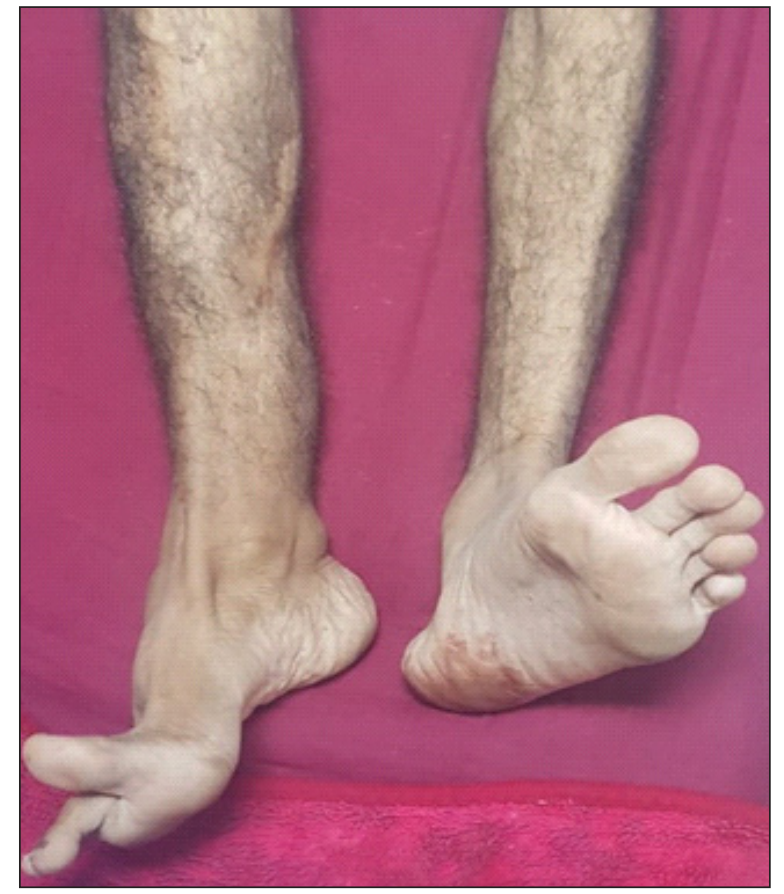

Fig 1: long and hypertrophied right lower limb with a prominent vein

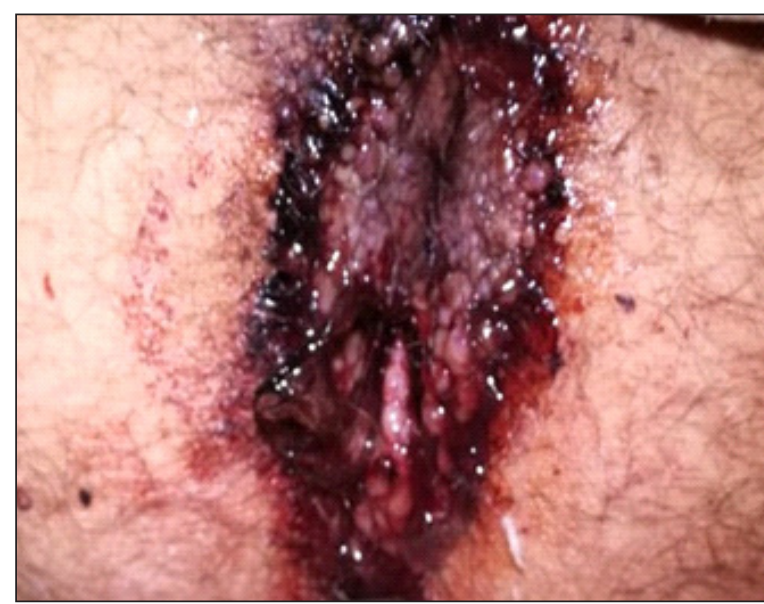

Fig 2: Perianal warts

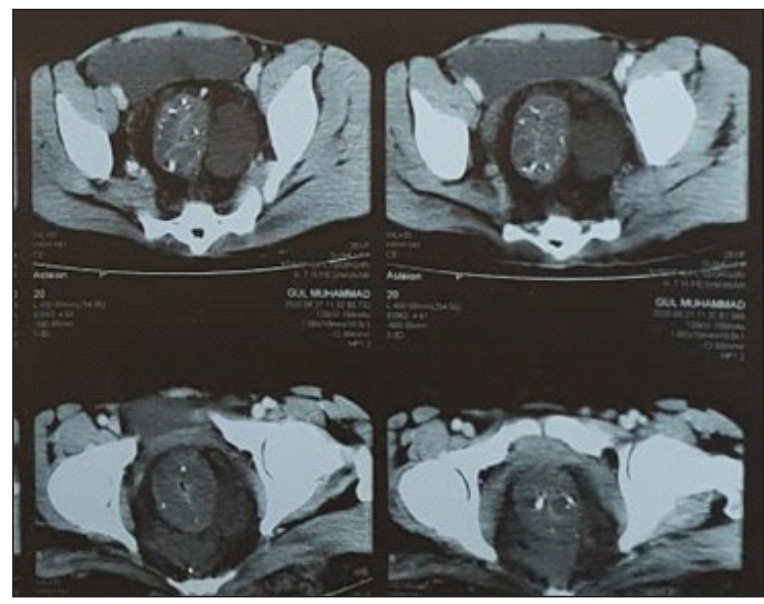

Fig 3: Vascular malformation along the rectal wall

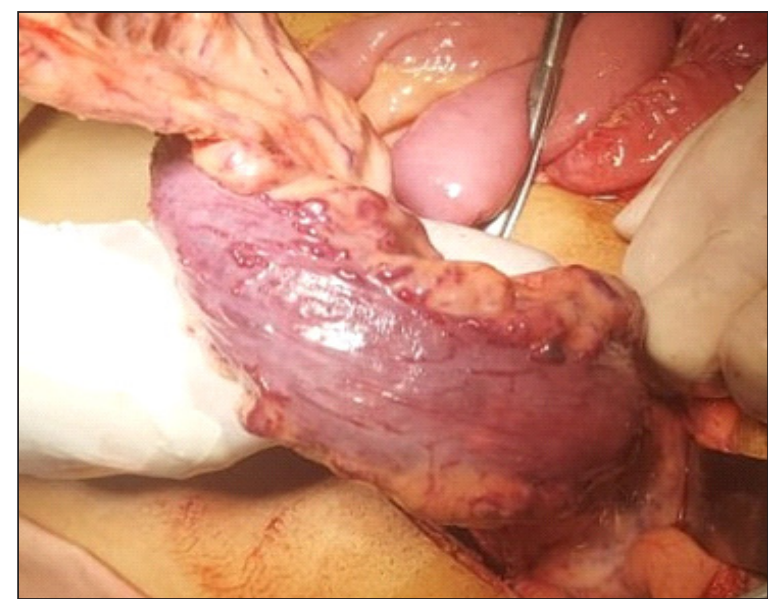

Fig 4: Preoperative image of Rectosigmoid hemangiomas

\section{DISCUSSION}

Besides the overlap of KTS with other vascular anomalies, the condition itself varies regarding the location and laterality. In $85 \%$ cases KTS is unilateral, in 12.5 $\%$ cases it is bilateral and in $2.5 \%$ cases it is reported crossed bilateral. ${ }^{6}$ Our case comes in the commonest cat- 
egory as right lower limb is involved sparing other limbs. As far the presentation is concerned, literature has reported different modes of presentation. Some patients report with limbs length disparity only while others come with few or multiple complaints as a direct consequence of the anomaly or its complications. More often the symptoms of varicose veins are annoying for patients. Serious presentations include per rectal bleeding and pulmonary embolism. ${ }^{7}$ The primary concern in our case was persistent per rectal bleeding requiring frequent transfusions, though all the classical features were there. Like the majority of cases reported, our patient had developed signs of the syndrome in early life but the diagnosis was delayed when he presented in our tertiary care setup in adulthood with serious morbidity.

Treatment of KTS is symptoms centered. Debulking surgery for morbid limb hypertrophy has not shown satisfactory results. Majority of patients undergo surgery for symptomatic varicose veins in early life..$^{8,9}$ As far per rectum bleeding is concerned, different modalities of treatment have been tried with different results. Depending upon the amount and site of bleeding, feeding vessels anatomy, general health and age of patients, injection sclerotherapy, laser photocoagulation, surgical resection of involved rectum/colon and chemoembolization are the known modalities attempted for the cessation of bleeding. ${ }^{10,11}$

\section{REFERENCES}

1. AlSheef M, Alotaibi H, Zaidi AR, Bauones S, Kullab GJ, AIShaikh M. Case Report: Klippel-Trenaunay SyndromeRecurrent Venous Thromboembolism and Vascular Malformation. Int Med Case Rep J. 2020 May 21;13:195-200.

2. Sahli H, Bachali A, Daas S, Ezzeddine Z, Bouzaidi K, Tekaya R. An Uncommon Presentation of Klip-
pel-Trenaunay Syndrome Presenting with Acute Hip Pain. J. adv. med. 2017:1-4.

3. Oda K, Morimoto D, Kim K, Yui K, Kitamura T, Morita A. Spinal cavernous angioma associated with Klippel-Trenaunay-Weber syndrome: case report and literature review. World Neurosurg. 2018 Jan 1;109:333-7.

4. Godoy JM, Río A, Domingo Garcia P, de Fatima Guerreiro Godoy M. Lymphedema in Klippel-Trenaunay Syndrome: Is It Possible to Normalize?. Case reports in vascular medicine. 2016 Jul 26;2016.

5. Chagas CA, Pires LA, Babinski MA, Leite TF. Klippel-Trenaunay and Parkes-Weber syndromes: two case reports. J Vasc. Bras. 2017 Dec;16(4):320-4.

6. Malgor RD, Gloviczki P, Fahrni J, Kalra M, Duncan AA, Oderich GS, Vrtiska T, Driscoll D. Surgical treatment of varicose veins and venous malformations in KlippelTrenaunay syndrome. Phlebology. 2016 Apr;31(3):20915.

7. Asnake ZT, Fishman TJ, Sun L, Salabei JK. Recurrent Venous Thromboembolism in a Patient with Klippel-Trenaunay Syndrome Despite Adequate Anticoagulation with Warfarin. Cureus. 2020 Apr;12(4).

8. Conway AM, Qato K, Tran NT, Short H, Giangola G, Rosen RJ, Carroccio A. Major limb amputations in patients with congenital vascular malformations. Ann Vasc Surg. 2020 May 18.

9. Then EO, Ofosu A, Rawla P, Sunkara T, Gaduputi V. Klippel-Trenaunay Syndrome, a rare cause of hematochezia. Gastroenterol Res Pract. 2018 Dec;11(6):426.

10. Pérez-Alfayate R, Martínez-Moreno N, Rosati SD, Moreu-Gamazo M, Pérez-García C, Martínez-Alvarez R. Klippel-Trenaunay-Weber Syndrome Associated with Multiple Cerebral Arteriovenous Malformations: Usefulness of Gamma Knife Stereotactic Radiosurgery in This Syndrome. World Neurosurg. 2020 Sep 1;141:425-9.

11. Wang SK, Drucker NA, Gupta AK, Marshalleck FE, Dalsing MC. Diagnosis and management of the venous malformations of Klippel-Trénaunay syndrome. Vasc. Surg. Venous. Lymphat. Disord. 2017 Jul 1;5(4):587-95. 